\title{
Triaxial tests to determine a microstructure-based snow viscosity law
}

\author{
Perry Bartelt, ${ }^{1}$ Markus von Moos ${ }^{2}$ \\ ${ }^{1}$ Swiss Federal Institute for Snow and Avalanche Research, CH-7260 Davos Dorf, Switzerland \\ ${ }^{2}$ Institute for Geotechnical Engineering (IGT), Swiss Federal Institute of Technology, ETH-Hönggerberg, CH-8093 Zürich, Switzerland
}

\begin{abstract}
This paper describes a new triaxial testing apparatus designed to determine the creep (viscoelastic) behavior of snow. The device is deformation-controlled and can apply strain rates between $10^{-7} \mathrm{~s}^{-1}$ and $10^{-2} \mathrm{~s}^{-1}$ in tension and compression. The sample volume change is determined by measuring the displaced pore-air volume. During winters $1997 / 98$ and 1998/99, > 100 compression and tension tests were carried out. It is shown that snow is a highly non-linear but ideal viscoelastic material with a strong strain-rate dependency. A selection of test results is provided. We show how snow viscosity varies with density and strain rate. In a final analysis we interpret our results with respect to snow microstructure in order to develop microstructure-based constitutive relations which can be implemented in finite-element programs. Our results clearly show that for snow densities and strain rates tested, straining of the grain bonds is the primary mechanism of deformation within the snow ice lattice.
\end{abstract}

\section{SNOW VISGOSITY}

Switzerland underwent an extreme avalanche period in February 1999. During this intense 1 month period, over 3000 avalanches occurred; 1000 of these caused damage to residential areas, agricultural land and power and transportation lines. Avalanche fracture heights of $>5 \mathrm{~m}$ were observed, indicating avalanche return periods of well over 100 years. A total of 17 people were killed, 12 alone in Evoléne, canton Valais.

Although tragic enough, the damage could have been greater had a new avalanche warning system not been in operation (Russi and others, 1998). An integral part of this warning system is the numerical modeling of the snowpack in order to augment information obtained from direct human observations and a large network of fully automated weather stations (Lehning and others, 1998). The model provides avalanche forecasters with supplementary information in cases where digging snow pits is impossible (bad weather), too time-consuming or simply too dangerous. The simulation program is described in Lehning and others (2000).

Warning specialists are primarily interested in knowing new-snow amounts and snowpack-settling rates after snowfall periods. This information is used directly to judge avalanche hazard. New-snow mass is determined indirectly by automatically measuring the location of the snowpack surface. However, the settlement of the snowpack must be theoretically calculated and then subtracted from this measured location in order to determine the true amounts of new snow. Since elastic deformations are small, the snow elasticity is of minor importance. The deformation rate is controlled by the amount of viscous deformation, i.e. the snow viscosity.

In this paper we briefly describe a new triaxial testing device that we use to perform short- (several minutes) and long-term (several days) creep tests in both tension and compression (see Fig. 1). Over 100 experiments using snow samples within the density range $180 \mathrm{~kg} \mathrm{~m}^{-3} \leq \rho \leq 400 \mathrm{~kg} \mathrm{~m}^{-3}$ were performed during winters 1997/98 and 1998/99.

Although triaxial tests have been performed in the past by Salm (1967, 1971, 1975, 1977), the test results have not been used to develop instationary microstructure-based constitutive relations which are valid for large deformations and strains. The work of Salm was used to formulate a macroscopic failure criterion for snow, based on conserved energy levels at

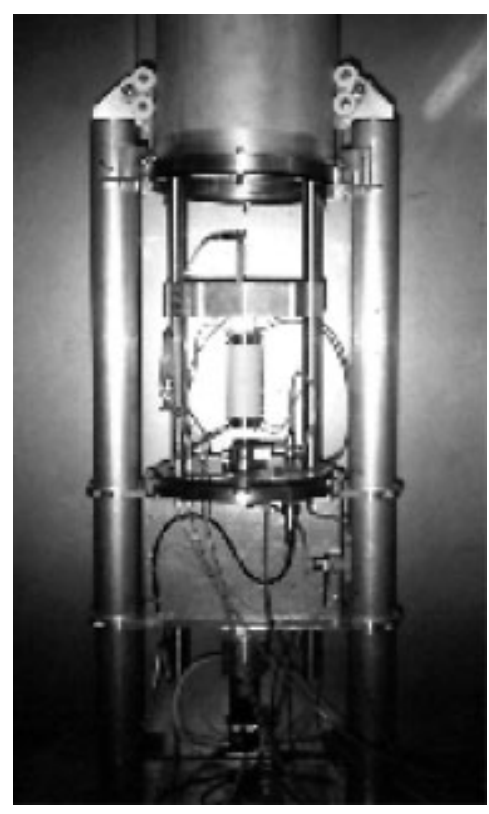

Fig. 1. The triaxial apparatus with snow sample. 
fracture. He clearly showed that the fracture strength of snow is dependent on strain history, but was not able to correlate fracture strength to snow microstructure.

Later, Mahajan and Brown (1993) proposed a constitutive law for snow, based on the dislocations of the grain bonds. However, this theory was limited to small strains. Two further deformation mechanisms, superplastic straining of the necks and inter-particle sliding between the grains, were also postulated to contribute to the overall material behavior. This constitutive model has been used in our operational snowpack simulation program with some success (Lehning and others, 1998, 2000). We have found that the introduction of the superplastic straining mechanism leads to too large and unrealistic snowpack settlements when compared to actual field measurements. Nonetheless, an important contribution of the work of Mahajan and Brown was to identify how microstructural processes can be extrapolated from macroscopic tests, such as triaxial experiments.

In the following, we first describe the triaxial apparatus. We then present the results of single-cycle creep tests in compression. In the conclusions we summarize the 100 test results and show how snow viscosity varies with density and applied strain rate. We then use this information to identify the stress state of the snow bonds and compare our measurements with the theoretical predictions of Mahajan and Brown (1993).

\section{THE TRIAXIAL APPARATUS}

\subsection{Design}

The design of our new triaxial apparatus deviates from standard triaxial testing devices used in soil mechanics in four ways:

1. The creep tests are not load-controlled but deformationcontrolled. Since all finite-element programs are based on determining the state of stress from the material strains or deformation, this simplifies the interpretation of the experimental results when formulating constitutive laws.

2. The lateral pressure is not applied by a fluid but by compressed air. A fluid produces a hydrostatic pressure which has a gradient from the top to the bottom of the sample. For snow, this is not acceptable since the maximum lateral pressure is only $30 \mathrm{kPa}$.

3. The loading frame and the load cell are both inside the pressure cell in order to avoid measuring any friction in the loading system.

4. The sample volume change is recorded by measuring the pore-air volume that is pressed out of the sample during compression. The determination of the volume change in a compressed-air triaxial apparatus is difficult since the samples must be airtight. Our specially designed volumetric measurement system will be explained later.

\subsection{Mechanical system}

The mechanical system is shown in Figure 2. The deformation-controlled testing device is driven by a step motor which propels a geared screwed spindle over a shaft coupling. The loading frame can be moved up and down at different rates. One step of the motor is equivalent to a micrometer

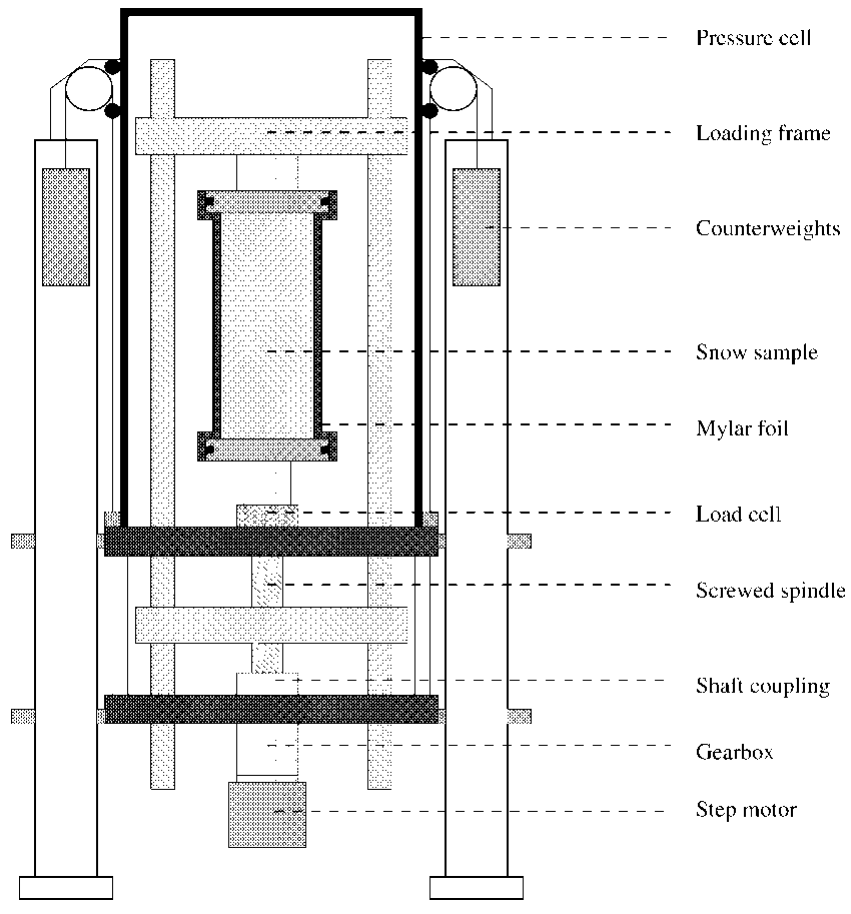

Fig. 2. The mechanical system.

feed. The $22 \mathrm{~kg}$ pressure cell is equipped with a counterweight lifting tackle and is sealed against the base plate with an O-ring. The cell is airtight.

The lateral pressure is produced by an air-pump that delivers a maximum of $30 \mathrm{kPa}$. The separation between snow sample and lateral pressure is guaranteed by a $12 \mu \mathrm{m}$ thick gas-tight Mylar foil, which is glued at the top and bottom of the sample to two PVC rings. These rings are attached to the loading plates when the sample is installed in the testing device. The mechanical specifications, including the sample size, are shown in Table 1.

\subsection{Control system}

The control of the machine and the entire data recording occurs automatically using two control units, an amplifier and a personal computer (PG) equipped with an analogto-digital transformer. The step motors of the loading frame and the volume-change measuring device both require a control unit. The data from all the measurement transducers are passed to the amplifier unit, to the control units and then to the PC. The air-pump for the lateral pressure is governed by a pressure regulator, which compares the actual to the prescribed value. The user-friendly PC program LAB-VIEW is used to input test specifications as well as to

Table 1. Specifications of triaxial apparatus

\begin{tabular}{ll}
\hline Property & Limits \\
\hline Sample size & $h=126 \mathrm{~mm}$ \\
& $d=58 \mathrm{~mm}$ \\
Deformation & $\Delta h_{\max }= \pm 50 \mathrm{~mm}$ \\
Strain rate & $\dot{\epsilon}_{\max }=2 \times 10^{-2} \mathrm{~s}-1$ \\
& $\dot{\epsilon}_{\min }=2 \times 10^{-7} \mathrm{~s}$ \\
Lateral pressure & $\alpha_{\max }= \pm 30 \mathrm{kPa}$ \\
Axial pressure & $\alpha_{\max }= \pm 750 \mathrm{kPa}$ \\
& \\
\hline
\end{tabular}




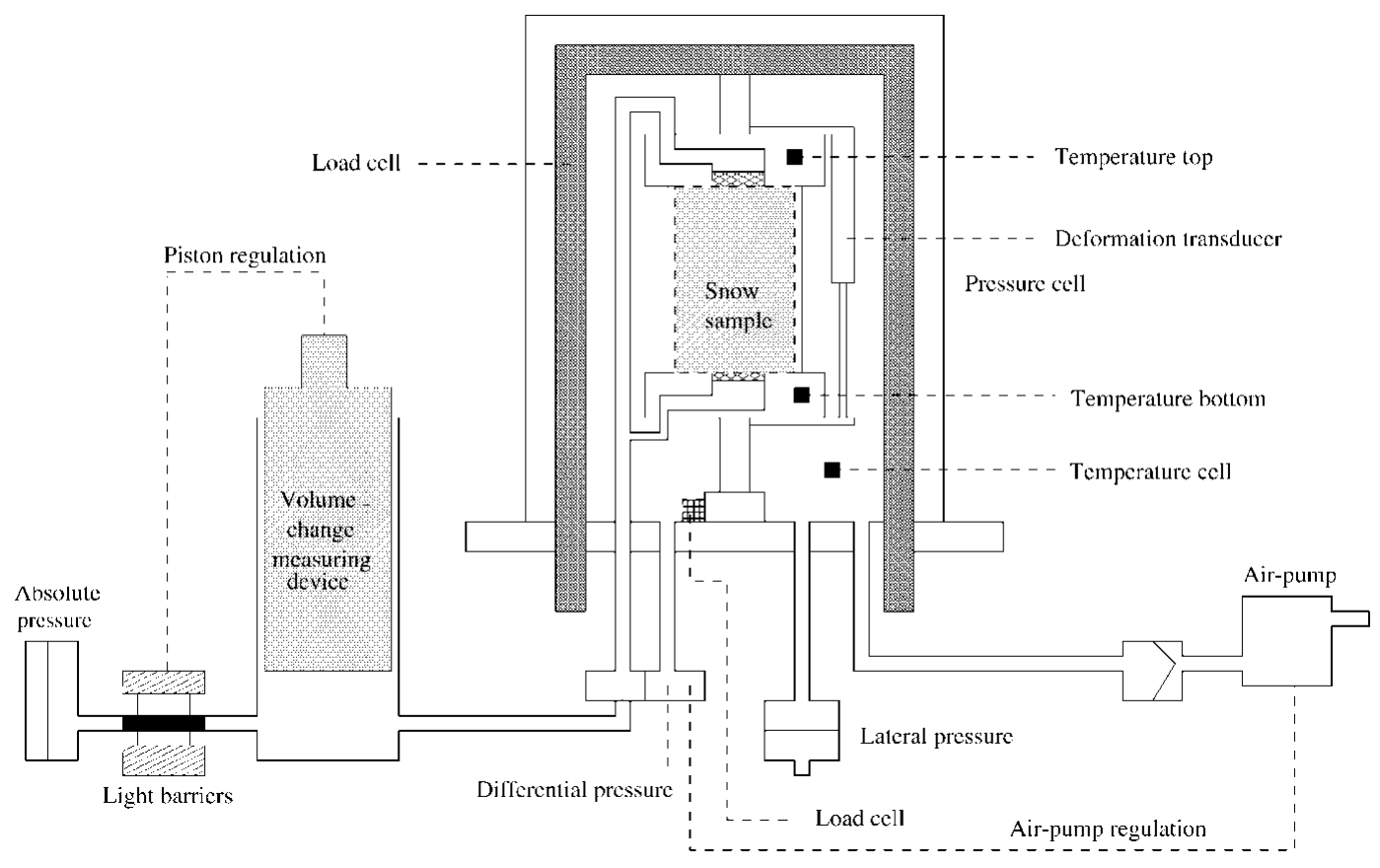

Fig. 3. Triaxial control system.

visualize the test results. Different deformation cycles (up, down, wait and stop), strain, strain rate and lateral pressure are set in an input menu before the test is started. The measured data (resisting force, volume change, temperature) can be monitored graphically during the tests.

Fail-safe switches are included in the control system so that the measured values stay within a realistic range. This prevents the machine and load cell from being damaged during a test.

\subsection{Volume-change measuring device}

A constant strain rate is applied to the snow sample as the tests are carried out in deformation control mode. The resisting force is measured by a load cell installed below the sample inside the pressure cell (see Fig. 2). The load cell is easily exchangeable. A cell which can measure up to $2 \mathrm{kN}$ is currently being used.

The relative displacement between the top and bottom loading plates is recorded and defines the axial deformation of the sample.

To check the air pressure in the two separated systems (pore-air system and lateral-pressure system) there are three transducers. One measures the lateral pressure relative to the pressure in the pore air of the sample. This value is used by the pressure regulator to govern the air-pump. A second transducer measures the lateral pressure relative to the atmospheric pressure. The third transducer measures the absolute pore-air pressure relative to a vacuum, and controls the volume-change measuring device. The temperature inside the pressure cell is recorded using three temperature sensors: one on the top load plate, one on the bottom load plate and one free in the air that surrounds the sample.

The volume-change measurement system is displayed in Figure 3 . The volume change over time caused by the deformation of the snow sample is measured by capturing the displaced pore air.

In this pore-air system a drop of antifreeze is placed in a
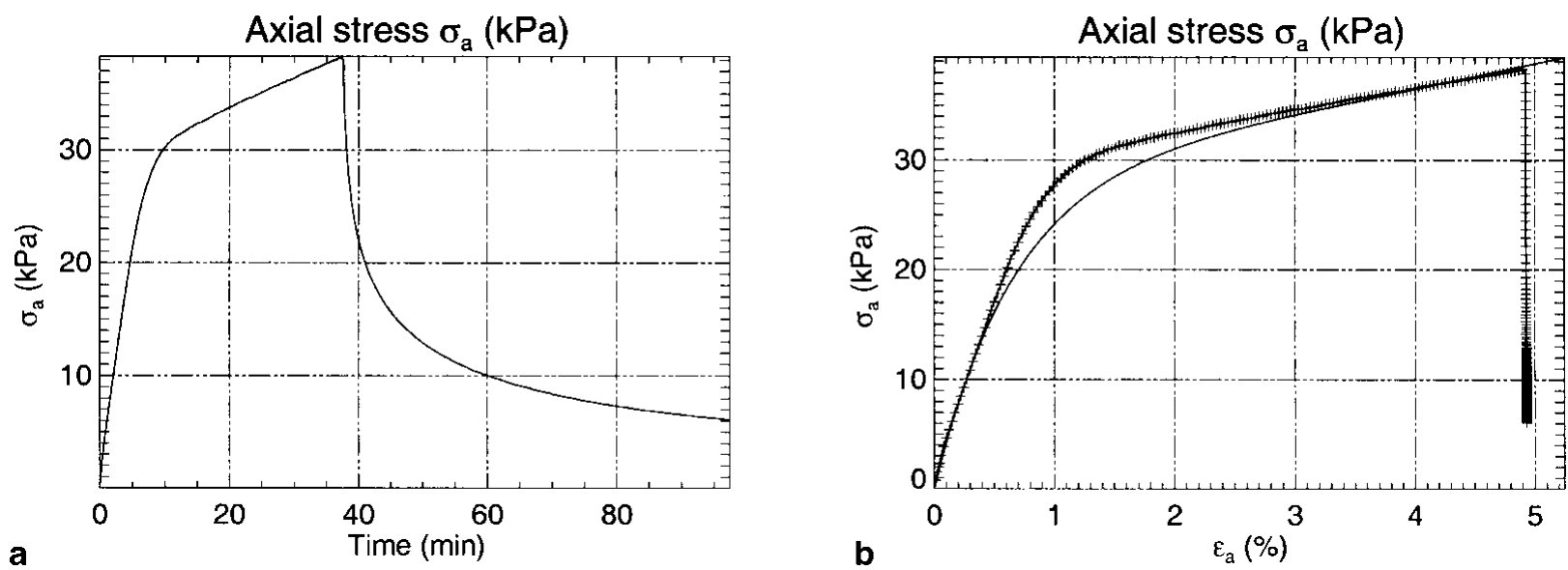

Fig. 4. (a) Measured axial stress $\sigma_{\mathrm{a}}$ of a compressive creep test. A snow sample with density $\rho=255 \mathrm{~kg} \mathrm{~m}^{-3}$, side pressure $\sigma_{\mathrm{r}}=$ $2.5 \mathrm{kPa}$ is loaded with a strain rate of $\dot{\epsilon}=2.2 \times 10^{-5} \mathrm{~s}^{-1}$ for $40 \mathrm{~min}$. (b) Comparison between measurements and simulation. A simple density-dependent Maxwell law matches the measurements well. The simulation results are denoted with a cross. The temperature of the tests was $T=-12.5^{\circ} \mathrm{C}$. 

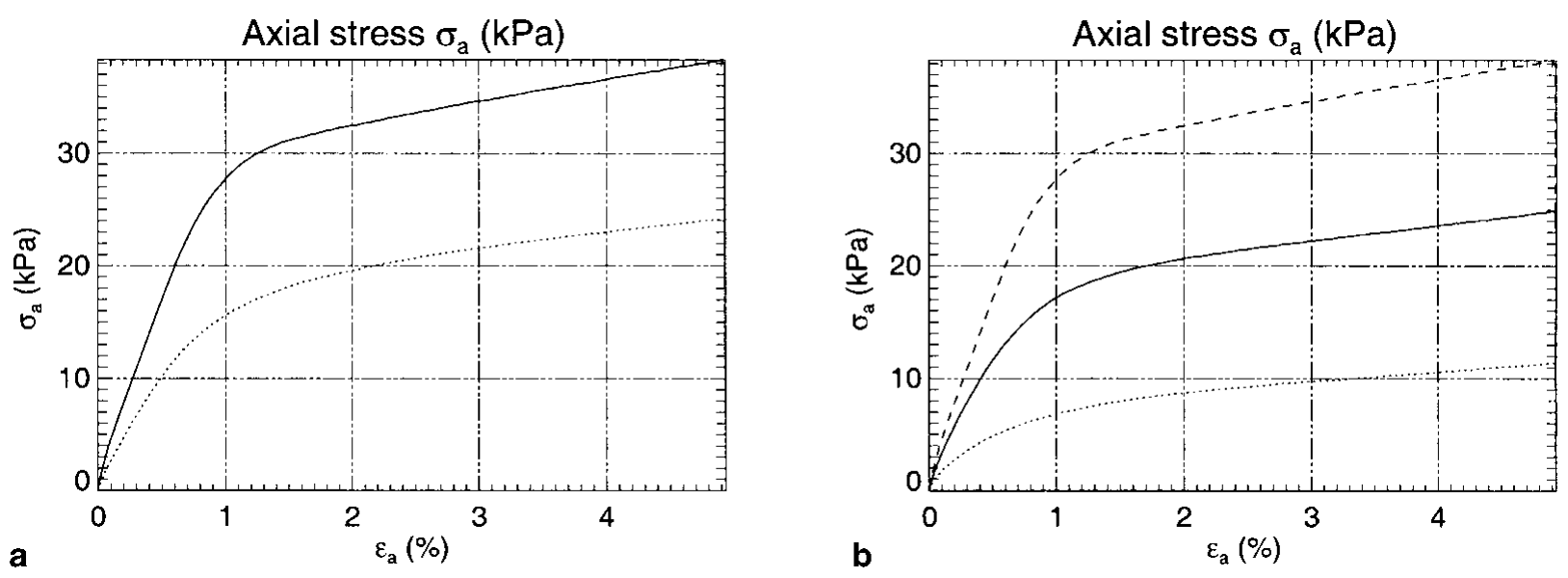

Fig. 5. (a) The influence of snow density on viscoelastic behavior. The larger the density, the larger the viscosity. Top curve: $\rho=$ $255 \mathrm{~kg} \mathrm{~m}^{-3}$. Bottom curve: $\rho=214 \mathrm{~kg} \mathrm{~m}^{-3}$. (b) The influence of applied strain rate on snow stress-strain behavior. Top curve: $\dot{\epsilon}=2.2 \times 10^{-5} s^{-1}$. Middle curve: $\dot{\epsilon}=4.2 \times 10^{-6} \mathrm{~s}^{-1}$. Bottom curve: $\dot{\epsilon}=7.4 \times 10^{-5} \mathrm{~s}^{-1}$. In both cases the temperature of the tests was $T=-12.5^{\circ} \mathrm{C}$.

small Plexiglas tube. This drop is positioned between two light barriers. In the beginning, both barriers are interrupted. When the snow sample is deformed, air flows out and the drop is pushed to either the left or the right of the light barriers. As soon as one barrier is free, a piston, which is connected to the pore-air system, is activated to bring the drop back to its original position. This process goes on step by step. The position of the piston, which is driven by a step motor, corresponds to the actual volume change.

At the end of the pore-air system a transducer measures the absolute pressure and compensates small pressure changes.

\section{FIRST RESULTS}

During the time period February-June 1998, >60 triaxial tests were performed on three snow types with different microstructure and density. Between January and May 1999, $>40$ triaxial tests were carried out. The densities varied between 180 and $440 \mathrm{~kg} \mathrm{~m}^{-3}$. The tests all contained one deformation cycle followed by a relaxation period. The tests were performed with different applied strain rates. In Figure 4 an example of a typical triaxial creep test is presented. The measured stress shows a steep rise in magnitude at the beginning of the experiment. A partly elastic behavior can be identified. Afterwards the curve flattens because the sample is creeping under constant applied strain rate. As soon as the applied deformation stops, i.e. strain rate is equal to zero, relaxation begins and the stress decreases very quickly. Figure $5 \mathrm{a}$ shows the large influence that small changes in density have on the resulting stress: high-density samples can resist high stresses. Except for density the test conditions were unchanged. Figure $5 \mathrm{~b}$ shows the influence of strain rate on the resulting stress: high strain rates create high stresses. The results are from a series of tests where only the strain rate was varied.

\section{DISGUSSION AND CONGLUSIONS}

The test series was analyzed using the classic rheological viscoelastic models of Maxwell, Kelvin and Burgers (see Mellor, 1975). This is the first step in formulating more com-

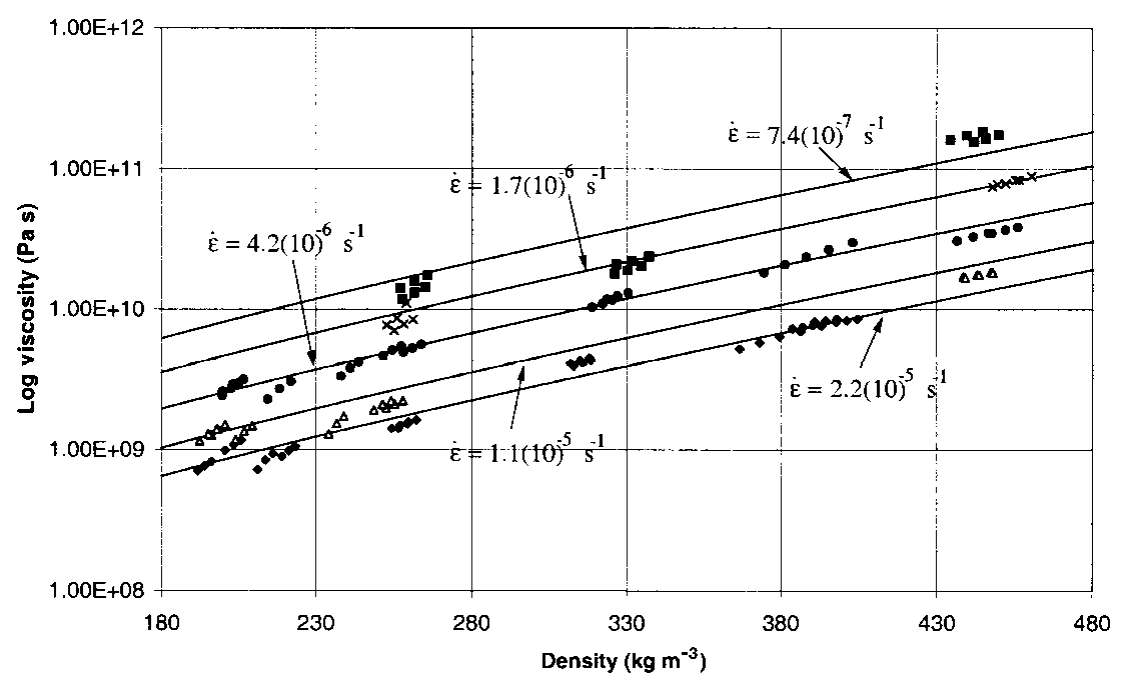

Fig. 6. Comparison between experimentally determined viscosity and constitutive model. Note the good agreement for all strain rates. Experimentally applied strain rates: diamonds $\dot{\epsilon}=2.2 \times 10^{-5} \mathrm{~s}^{-1}$, triangles $\dot{\epsilon}=1.1 \times 10^{-5} \mathrm{~s}^{-1}$, circles $\dot{\epsilon}=4.2 \times 10^{-6} \mathrm{~s}^{-1}$, crosses $\dot{\epsilon}=1.7 \times 10^{-6}{ }^{-1}$, squares $\dot{\epsilon}=7.4 \times 10^{-7} \mathrm{~s}^{-1}$. 


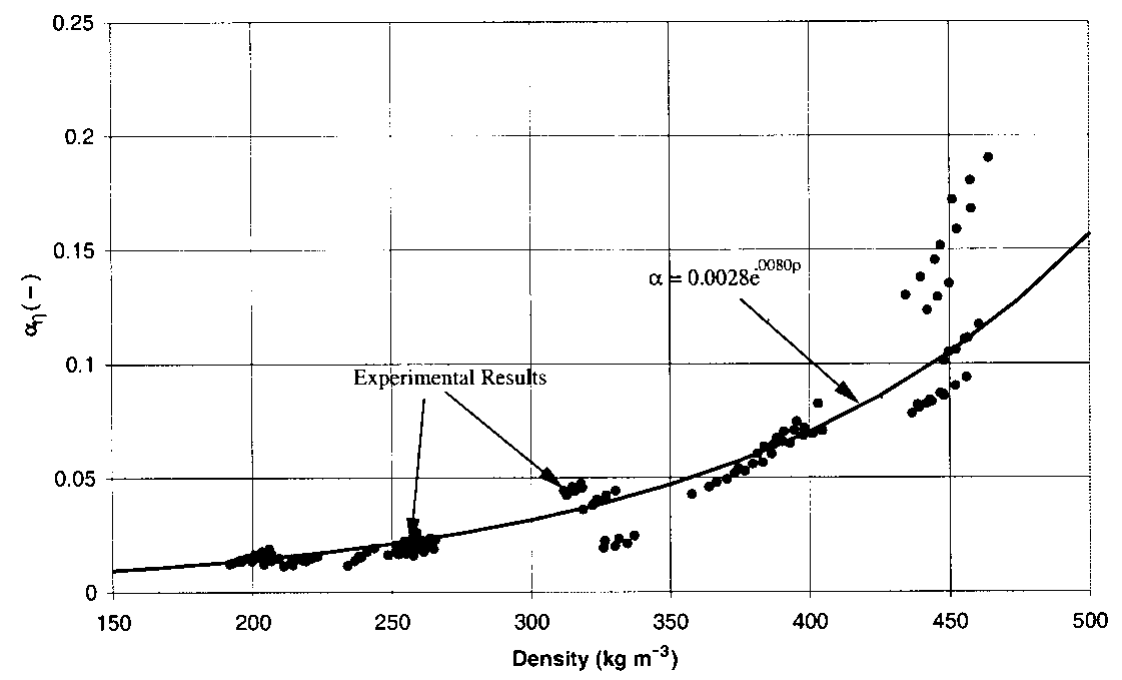

Fig. 7. The parameter $\alpha_{\eta}$ indicates the percentage of the ice lattice that is resisting deformation. The thick curved line is an exponential fit to the test results: $\alpha_{\eta}=0.0028 \mathrm{e}^{0.0080 \rho}$. The experimental results indicate $\alpha_{\eta}$ lies in the range $2-20 \%$.

plex and accurate constitutive relations. The goal was, first, to qualitatively characterize snow as a viscoelastic material, and then in a second step to introduce laws that account for snow microstructure and densification.

As an example, consider Figure $4 \mathrm{~b}$ which shows a measured stress curve compared to a Maxwell model in which the viscosity is density-dependent. The Maxwell model, which is presently being employed in our snowpack model, can only be used to model the loading phase of the tests; it cannot model the relaxation phase.

A summary of the $>100$ tests is provided in Figure 6 . This graph displays the Maxwell snow viscosity as a function of the snow density. The experimental results clearly show an important and previously undocumented phenomenon: snow of a given density exhibits higher viscosity at lower strain rates. Previous experimental results have shown an increase in viscosity only when the density increases (Mellor, 1975). This material behavior is also demonstrated by ice at higher stress (Sanderson, 1988). In snow, such stresses exist at the inter-granular bonds of the ice-crystal lattice. Thus, we believe we have detected a microstruc- tural phenomenon in our tests. This is an important result since it shows how the influence of snow microstructure can be introduced in macrostructural constitutive laws. Furthermore, it explains the inability of existing viscosity formulations to model simple settlement experiments (Bartelt and Christen, 1999). These laws have no strain-rate effect. In order to show exactly how the influence of snow microstructure can be introduced into a constitutive model, we first define the dimensionless parameter $\alpha_{\eta}$,

$$
\alpha_{\eta}=\frac{\sigma_{\mathrm{s}}}{\sigma_{\mathrm{i}}} \frac{\rho_{\mathrm{i}}}{\rho_{\mathrm{s}}},
$$

where $\sigma_{\mathrm{s}}$ is the applied snow stress, $\rho_{\mathrm{s}}$ and $\rho_{\mathrm{i}}$ are the density of snow and ice, respectively, and $\sigma_{\mathrm{i}}$ is the ice stress which we define, in general, according to any constitutive law for ice, for example,

$$
\sigma_{\mathrm{i}}=\eta_{\mathrm{i}} \dot{\epsilon} .
$$

In our case we are using the viscosity, $\eta_{\mathrm{i}}$, of Barnes which is based on experiments (Sanderson, 1988). Physically, the parameter $\alpha_{\eta}$ indicates how much ice mass is actually resisting deformation. In our experiments we found $0.02 \leq \alpha_{\eta} \leq 0.20$

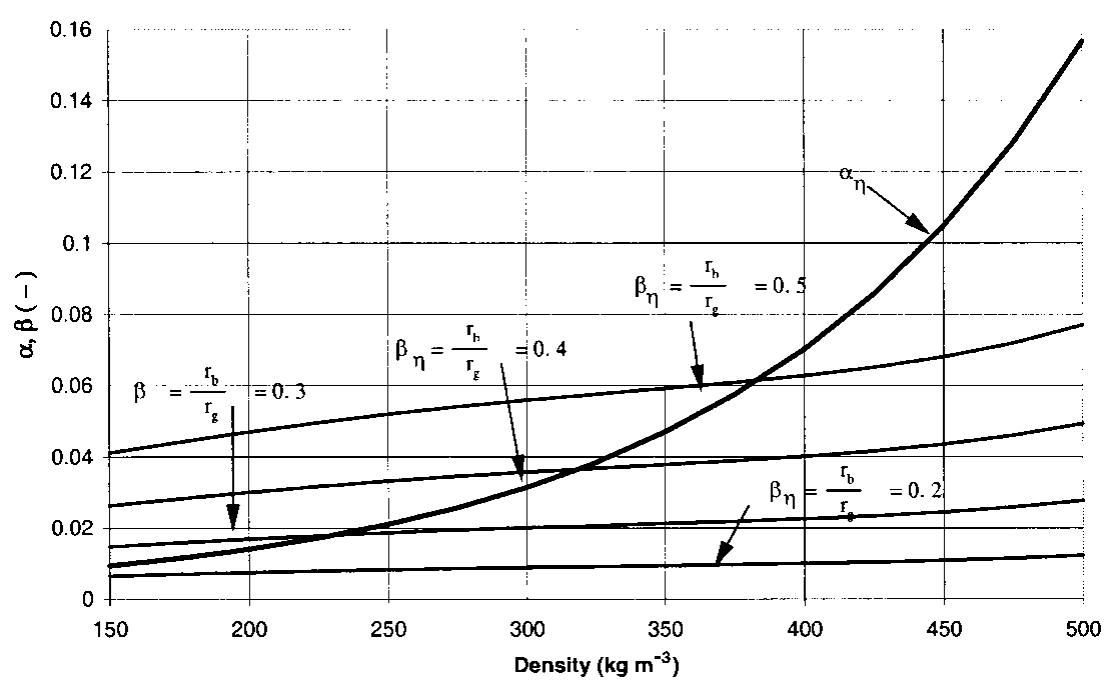

Fig. 8. A comparison between $\alpha_{\eta}$ and $\beta_{\eta}$. The straight lines are the theoretical predictions of Mahajan and Brown for constant $r_{\mathrm{b}} / r_{\mathrm{g}}$ ratios. The lower line $r_{\mathrm{b}} / r_{\mathrm{g}}=0.2$; upper line $r_{\mathrm{b}} / r_{\mathrm{g}}=0.5$. Note the good agreement between theory and experiment for low-density snow. 
(see Fig. 7). In other words, $2-20 \%$ of the total ice in the crystal lattice contributes to the mechanical resistance of snow. This information can be compared to theoretical predictions. Mahajan and Brown (1993) derived the dimensionless microstructural parameter (which we have termed $\beta_{\eta}$ ),

$$
\beta_{\eta}=\frac{N_{3}}{4 \pi}\left(\frac{r_{\mathrm{b}}}{r_{\mathrm{g}}}\right)^{2}
$$

using a spherical grain-bond model. $N_{3}$ is the snow coordination number, $r_{\mathrm{b}}$ and $r_{\mathrm{g}}$ are the bond and grain radius, and the parameter $\beta_{\eta}$ relates the stress state of the bonds or necks, $\sigma_{\mathrm{n}}$, to the applied macroscopic snow stress, $\sigma_{\mathrm{s}}$,

$$
\sigma_{\mathrm{s}}=\beta_{\eta} \frac{\rho_{\mathrm{s}}}{\rho_{\mathrm{i}}} \sigma_{\mathrm{n}} .
$$

The parameter $\beta_{\eta}$ is derived based on the idea that dislocation straining of the ice necks is the primary deformation mechanism in the ice lattice, relative to superplastic straining and inter-particle sliding. The parameter $\beta_{\eta}$ is plotted in Figure 8. These are the series of straight lines that intersect the exponential fit to the experimental results. The fact that both the experimental $\alpha_{\eta}$ and theoretical $\beta_{\eta}$ values have the same order of magnitude reflects the validity of the theory. As snow metamorphism advances, it is expected that the $r_{\mathrm{b}} / r_{\mathrm{g}}$ ratios increase with increasing density. The experimental results show that $r_{\mathrm{b}} / r_{\mathrm{g}}$ ratios are not constant over time.

The ratio

$$
n=\frac{\alpha_{\eta}}{\beta_{\eta}}
$$

indicates how much of the mechanical resistance of the sample is being controlled by dislocation straining of the ice bonds. We measured $r_{\mathrm{b}}, r_{\mathrm{g}}$ and $N_{3}$ using stereological thin sections and found $n \approx 0.8$ and higher for both highand low-density snow. We can therefore conclude from our analysis that dislocation straining of the ice bonds for the densities and strain rates considered in our triaxial tests is the dominant mechanism of deformation. For high-density snow, high values of $r_{\mathrm{b}} / r_{\mathrm{g}}$ are required to match the experimental results, so the constitutive theory of Mahajan and Brown does not seem to apply.

Another important conclusion that can be drawn from the results is that new-snow bond-to-grain ratios are in the range $0.1 \leq r_{\mathrm{b}} / r_{\mathrm{g}} \leq 0.2$. This information is used to establish the initial microstructural conditions for our operational avalanche-forecasting models.

Finally the test results indicate very clearly that a consti- tutive law for snow viscosity, $\eta_{\mathrm{s}}$, can be formulated in terms of $\eta_{\mathrm{i}}$, the ice viscosity:

$$
\eta_{\mathrm{s}}=\alpha_{\eta} \eta_{\mathrm{i}} \frac{\rho_{\mathrm{s}}}{\rho_{\mathrm{i}}}=n \beta_{\eta} \eta_{\mathrm{i}} \frac{\rho_{\mathrm{s}}}{\rho_{\mathrm{i}}} .
$$

A comparison between the constitutive law and the experimental results is shown in Figure 6. This constitutive formulation has two advantages: the strain-rate effect so apparent in the experiments is included via the ice viscosity law $\eta_{\text {i, }}$ and the microstructural parameters are included via the parameter $\beta_{\eta}$.

\section{AGKNOWLEDGEMENTS}

We thank the Swiss National Science Foundation for financial support for this project. We also thank B. Salm for his helpful advice.

\section{REFERENGES}

Bartelt, P. and M. Christen. 1999. A computational procedure for instationary temperature-dependent snow creep. In Hutter, K., Y. Wang and H. Beer, eds. Advances in cold-region thermal engineering and sciences: technological, environmental, and climatological impact. Berlin, etc., Springer-Verlag, 367-386. (Lecture Notes in Physics 533.)

Lehning, M., P. Bartelt and R. Brown. 1998. Operational use of a snowpack model for the avalanche warning service in Switzerland: model development and first experiences. In Hestnes, E., ed. 25 Tears of Snow Avalanche Research, Voss 12-16 May 1998. Proceedings. Oslo, Norwegian Geotechnical Institute, 169-174. (NGI Publication 203.)

Lehning, M., J. Doorschot and P. Bartelt. 2000. A snowdrift index based on SNOWPACK model calculations. Ann. Glaciol., 31 (see paper in this volume).

Mahajan, P. and R. L. Brown. 1993. A microstructure-based constitutive law for snow. Ann. Glaciol., 18, 287-294.

Mellor, M. 1975. A review of basic snow mechanics. International Association of Hydrological Sciences Publication 114 (Symposium at Grindelwald 1974-Snow Mechanics), 251-291.

Russi, T., W. Ammann, B. Brabec, M. Lehning and R. Meister. 1998. Avalanche warning 2000. In ISSW'98. International Snow Science Workshop, 27 September-1 October 1998, Sunriver, Oregon. Proceedings. Seattle, WA, Washington State Department of Transportation, 146-153.

Salm, B. 1967. An attempt to clarify triaxial creep mechanics of snow. In Ōura, H., ed. Physics of snow and ice. Vol. 1, Part 2. Sapporo, Hokkaido University. Institute of Low Temperature Science, 857-874.

Salm, B. 1971. On the rheological behavior of snow under high stresses. Contrib. Inst. Low Temp. Sci., Ser. A 23, 1-43.

Salm, B. 1975. Constitutive equation for creeping snow. International Association of Hydrological Sciences Publication 114 (Symposium at Grindelwald $1974-$ Snow Mechanics), 222-235.

Salm, B. 1977. Snow forces. F. Glaciol., 19(81), 67-100.

Sanderson, T. J. O. 1988. Ice mechanics: risks to offshore structures. London, etc., Graham and Trotman. 